\title{
Investigating Affordances of Virtual Worlds for Real World B2C E-Commerce
}

\author{
Minh Quang Tran \\ Department of Computing \\ The Open University, UK \\ Milton Keynes, MK7 6AA \\ m.tran@open.ac.uk
}

\author{
Shailey Minocha \\ Department of Computing \\ The Open University, UK \\ Milton Keynes, MK7 6AA \\ s.minocha@open.ac.uk
}

\author{
Dave Roberts \\ Department of Computing \\ The Open University, UK \\ Milton Keynes, MK7 6AA \\ d.roberts@open.ac.uk
}

\author{
Angus Laing \\ School of Business and Economics \\ Loughborough University, UK \\ Leicestershire, LE11 3TU \\ a.w.laing@lboro.ac.uk
}

\author{
Darren Langdridge \\ Department of Psychology \\ The Open University, UK \\ Milton Keynes, MK7 6AA \\ d.langdridge@open.ac.uk
}

\begin{abstract}
Virtual worlds are three-dimensional (3D) online persistent multi-user environments where users interact through avatars. The literature suggests that virtual worlds can facilitate real world business-to-consumer (B2C) e-commerce. However, few real world businesses have adopted virtual worlds for B2C e-commerce. In this paper, we present results from interviews with consumers in a virtual world to investigate how virtual worlds can support B2C e-commerce. A thematic analysis of the data was conducted to uncover affordances and constraints of virtual worlds for B2C e-commerce. Two affordances (habitability and appearance of realness) and one constraint (demand for specialised skill) were uncovered. The implications of this research for designers are (1) to provide options to consumers that enable them to manage their online reputation, (2) to focus on managing consumers' expectations and (3) to facilitate learning between consumers.
\end{abstract}

Consumer experience, e-commerce, interaction design, qualitative research, virtual worlds.

\section{INTRODUCTION}

This paper investigates affordances of virtual worlds that are relevant for business-to-consumer (B2C) e-commerce. Virtual worlds are threedimensional (3D) online persistent multi-user environments where users interact through avatars. Virtual worlds can potentially be used as an additional retail channel in multi-channel consumption (Bourlakis et al., 2009). Furthermore, compared to existing channels on the Web, virtual worlds can provide consumers with a more engaging consumer experience (Hemp, 2006).

Virtual worlds are being utilised by consumers to learn about real world products (Ganis et al., 2008). Eventually, consumers will be able to make real world purchases in virtual worlds as well (see for e.g. www.nearglobal.com and www.avayalive.com). Some of the advantages of virtual worlds for ecommerce are the ability to browse through virtual stores, view products in $3 \mathrm{D}$, communicate with other consumers and receive personalised advice from sales personnel (Park et al., 2008).
The aim of the study reported in this paper was to investigate the affordances of virtual worlds that can facilitate and support B2C e-commerce. Based on our investigations, we outline some design considerations for designers and usability practitioners.

The study was conducted in Second Life (www.secondlife.com). Second Life is a virtual world which was launched in 2003 and continues to remain popular. There are typically 40,000 concurrent users logged in at any time in Second Life. Second Life supports a diverse range of domains including education, training, gaming, ecommerce and social networking. The study focused on the e-commerce domain and specifically on the consumption process.

\section{RESEARCH QUESTION}

Despite the potential, very few retail businesses are employing virtual worlds for real world B2C ecommerce (Hansen, 2009). The lack of use and limited success of businesses in virtual worlds may be due to a lack of understanding about how to 
effectively utilise the affordances of virtual worlds to achieve business-oriented goals.

Our research question was "which affordances of virtual worlds facilitate the consumption process in virtual worlds?" This question was investigated through semi-structured interviews with consumers in Second Life. A thematic analysis was then performed on the interview data. While this study is based in Second Life, our goal has been to provide research outcomes that are relevant to $\mathrm{e}$ commerce in virtual worlds in general.

\section{DATA COLLECTION}

We conducted interviews with consumers (participants) who had consumption experiences in Second Life. The recruitment and interview protocol was verified and approved by our university's ethics committee. To search for and recruit participants, we visited shopping areas in Second Life. An instant message (IM) was sent in-world (within Second Life) to consumers inviting them to participate in the research study. Those who agreed were given further information about the study and then asked to provide consent to participate.

Ten males and twelve females participated. The genders refer to real life genders and not avatar genders. Participants' real life ages ranged from 20 to 50 . The ages provided by participants were assumed to be their true age. Participants came from different parts of the world, including USA, UK, Germany, Finland, Australia, Chile and the Netherlands. All the interviews were conducted in Second Life using in-world instant messaging. The interviews typically lasted 1 hour and 15 minutes. All interviews were conducted in English.

The interviews started with questions about participants' general experience with virtual worlds. Then participants' were asked to describe one shopping experience they had in Second Life. Participants were allowed to describe an experience involving virtual items since having an experience involving real world items is rare in Second Life. Although the motivation and outcomes of buying real world items compared to virtual items may be different, we believe the processes and affordances involved would be the same. For example, the stages in the consumption process (also called the service encounter) will be similar for real and virtual items. In both cases, participants recognize a consumption need, search for products, deliberate, make a purchase transaction and then form an overall evaluation of the experience (O'Keefe and McEachern, 1998). As participants recalled their experiences, they were encouraged to elaborate on details about what happened during each stage of the consumption process.

\section{DATA ANALYSIS}

The data analysis method was thematic analysis (Braun and Clarke, 2006). The analysis was guided by our research question: to identify the affordances of virtual worlds that facilitate the consumption process. The analysis involved generating codes and consolidating the codes into themes.

Codes were generated by annotating salient segments of the data. Salience was determined by the research question (Buetow, 2010). Since we were investigating affordances, we coded the data segments that referred to the technical features of virtual worlds that supported the consumer's interactions. The codes were then refined into a small set as shown below. The codes were consolidated into three themes: interaction mode, visual appearance and interaction capabilities.

- Theme 1: Interaction mode

o Embodied (visible) interactions

o Real-time interactions

- Theme 2: Visual appearance

o 3D environment

o Avatars

- Advanced graphics

o Real world like

- Theme 3: Interaction capabilities

o Linking to websites

- Support for range of activities

- Content creation tools

o In-world search capability

o Personal user inventory

o Social network support

o Teleportation

o Information embedded in objects

The themes were re-interpreted as affordances and constraints of virtual worlds. Based on the theme of interaction mode, we derived the affordance of 'habitability'. Based on the theme of visual appearance, we derived the affordance of 'appearance of realness'. Based on the theme of interaction capabilities, we derive the constraint of 'the demand for specialised skill'. These two affordances and one constraint are discussed in the next section.

\section{AFFORDANCES AND CONSTRAINTS}

\subsection{Virtual worlds are habitable}

Virtual worlds are populated with real people who spend time in-world working, playing and socialising. Therefore, consumers coming to shop 
in virtual worlds should expect to find other people who are already there. The presence of other people facilitates inter-personal interaction during the consumption process.

Consumer20: lots of people to talk to [...] you'll get lots of places to go to then and lots of help too and [people to] share your opinions with. Interviewer: Did you interact with any other customers or friends in the store? Consumer20: Yup so it was fun lol. They were all around at that time.

In order to be habitable, virtual worlds need to persistent. A persistent world allows consumers to re-visit the world. Thus it creates a sense of continuity in the experience. Consumers can reasonably expect the environment to remain the same so that they can pause their shopping and resume it another day.

Consumer2: I took a look and there is so much nice kilt's. I needed a long time to choose one because everything looks nice. So after 2 days I chose [one].

Persistence, however, does not mean that virtual worlds are static. On the contrary, virtual world environments are constantly changing. Consumers change the virtual world environment through their actions. For example, consumers can create, edit and delete objects which effects how the world appears to other consumers.

The avatar is also a dynamic element of the environment. Sometimes, seeing other avatars can influence the consumption process.

Consumer1: If you see somebody wearing something you like and it's [an object] you can inspect the [object] and see who made it. So I saw a guy with hair I liked and I inspected it and saw who made it. So I went to his store.

The presence of other people does not always have a positive effect on consumers. Other people can sometimes impede the consumption process. The nature of a multi-user environment means that the environment is shared with other users. Some design features can make this fact worse. For example, limits on the number of avatars allowed in one room means some consumers have to wait before they can enter a store.

Consumer5: I got really frustrated because [...] । had to walk over and really there were 30 avatars trying to walk over at the same time... and only one at a time could make it.

Nevertheless, there are positive outcomes of having other people present in a virtual world. A key advantage is development of social networks and communities. Consumers can easily make friends. The social atmosphere can trigger and facilitate the consumption process.

Consumer18: A friend of mine gave me a gift of a pair of shoes from the shop. I wanted to go check it out and see if they had another shoe that I liked. I didn't have time till just a little bit ago so I went. Got there looked around found four pairs of shoes I wanted and got them all at great prices.

The affordance of habitability is also related to events and activities in virtual worlds. Events add a sense of liveliness and make it clear that virtual worlds are a place where people work, play and socialise. Some events are related to consumption, such as parties for the new release of products.

Consumer5: We both couldn't wait for the day of the release. [...] I actually set my [real life] alarm to 5 am or something just so I could be one of the first persons to get [the product].

\subsection{Virtual worlds have an appearance of realness}

Virtual worlds are designed to be world-like. Consumers coming to shop in a virtual world should expect to find the retail environments resemble real world places in appearance. The retail environments in virtual worlds are typically designed to resemble real world department stores. The resemblance is appealing to some consumers.

Consumer11: I couldn't quite believe the detail. $\mathrm{He}$ had very cleverly lined the drive with items for sale. [...] We were then left to wander around and look on our own. Once again the detail astounded me. It made me feel like I had to have it.

The design of stores in virtual worlds is not constrained by real world factors, such as gravity and weather. This allows elements of fantasy, such as floating stores and impossibly high walls, to be included in the design.

Consumer8: I entered the store itself, which is like this, well almost, maze one could say, of walls and walls and on each wall there are [pictures] that show the products on sale.

However, the influence of real world store designs remains evident in virtual world stores.

Consumer9: [The stores were] as varied as you would find in the real world... though some were a bit maze-like in structure. Some were [in malls], some were free standing structures, some were in the sky, some were outdoor markets, some were fancy elegant places, some were rural, run down and rustic.

The resemblance to real world department stores applies to the appearance inside virtual world 
stores as well. Inside virtual world stores, products are typically arranged on shelves and walls, with the store's products organised into departments and classified as they would be in the real world. This further adds to a sense of familiarity for the shopping experience.

Consumer1: [The store] was departmentalised, fairly logical in layout. Walls and kiosks with boxes displaying the product [...] made to resemble an American department store.

Familiarity has another advantage of allowing consumers to use existing real world strategies to help them find their way around the stores and the virtual world.

Consumer9: I looked for signs pointing to the men's section, just as real life.

Consumer18: It was a small shop and with models in the centre of the room. [...] 2 female avatars on pose stands wearing their own outfits and shoes made by the shop [...] You can see what the item looks like before you spend money on it.

Finally, the appearance of realness also refers to the appearance of the consumers themselves. Each consumer is represented by 3D avatar in the form of a human. Thus, consumers can make movements and gestures in virtual worlds which have the appearance of real world movements and gestures.

\subsection{Virtual worlds demand specialised skills and knowledge}

Virtual worlds have many interface options and interaction capabilities. This can be a constraint for users who are new to virtual worlds. This theme is somewhat contradictory to the previous theme related to the appearance of realness. It seems that since virtual worlds mimic the real world, the interactions in virtual worlds should be natural and intuitive. However, this is not the case. The consumer must acquire special skill and knowledge about how to interact with the objects in the virtual world.

Consumer19: I try to find out [solutions] myself. This is an interactive world so I try to be as interactive as I can with the system. Interviewer: What do you mean by 'interactive'? Consumer19: Usually there is enough info about the item I want to buy 'under' it. I use the [context menu] and help myself.

Knowing how to use virtual worlds is critical for completing the consumption process.

Consumer9: Getting to some places and seeing that they did not, in fact, carry [the item] as per their keywords, was a bit irritating
Interviewer: What were they selling instead? Consumer9: Women's stuff, nothing for men at all. [...] [The advertisers] had included keywords in search that indicated the presence of men's clothing.

Almost all consumers in our study were experienced and knowledgeable virtual world users. Thus, all of the consumers were successful in resolving the problems that arose during the consumption process. Many knew about advanced techniques to optimise the virtual world interface.

Consumer10: I first click off the annoying red arrow that indicates where I am to go, then I step a few steps to the left or right to clear the landing point so no one lands on my head.

Consumers in this study also had the skill to control their avatar effectively. For example, Consumer17 uses a simple trick to allow her to change clothing in public without exposing her avatar.

Interviewer: Was there a changing area? Consumer17: [No] I always wear my [old] shirt and then I click and wear the other. I believe some people go home, take off their shirt first so they are topless and then wear the other shirt. But I wear the shirt and click on the other shirt so I won't be topless.

Skills and knowledge for using virtual worlds also includes social skills and having a network of friends. In other words, consumers should know how to interact in social situations in virtual worlds. The social interactions can influence the outcome of the consumption experience.

Consumer5: I was actually trying to talk to people there so it wouldn't be that boring... and no one really answered [...] I think the fact that people were ignoring me there [at the store] was the cherry on top of it. So I would almost say that was what made it so hardcore disappointing.

Controlling camera angles and the perspective in virtual worlds is also a valuable skill that consumers in our study had. This skill enables consumers to search and browse stores more effectively.

Consumer15: I also liked the layout of the store, walls were built up high and all the [products] were on all the walls, so you didn't need to walk anywhere and get lost, you just needed to spin around and use your camera controls to look up and up and up.

\section{IMPLICATIONS FOR DESIGN}

\subsection{Implications of habitability}

Habitability enables shopping alongside others in a persistent, but dynamic, e-commerce environment. Other consumers who are online discuss, review 
and recommend products, which influence the consumer's e-commerce experience (Kozinets, 1999). Typically, these discussions have been mediated through websites.

Virtual worlds are another platform for online communities to discuss products and services. One difference between websites and virtual worlds, however, is the degree of anonymity provided to consumers. In virtual worlds, consumer's interactions occur in a multi-user 3D space where actions are made visible to other consumers. Furthermore, consumers' avatars retain information about their interaction history; and not only their consumption-related interactions, but all other interactions they perform in the virtual world. Thus, consumers and their avatars develop can reputation through their history of interactions (Adrian, 2008).

One design consideration should be about how to give consumers more control to manage the development of their online reputation. Some factors, such as visibility of the avatar and personal privacy settings (data logging, disclosure of information, etc.) can help consumers manage their reputation in virtual worlds. Designers may also want to consider options to shop in private: for example, by allowing the consumer to be invisible or instantiating (constructing) a separate area in the store for consumers.

\subsection{Implications of appearance of realness}

The appearance of realness entails shopping in a familiar looking but novel environment. Familiarity of appearance is likely to influence consumers' expectations. Since virtual worlds look like the real world, they may expect interactions to be similar to the real world. Furthermore, the current design of virtual worlds is reinforcing these expectations. Interactions in virtual worlds are currently designed to mimic interactions in the real world, such as walking, communicating in real-time and using gestures. Objects in virtual worlds also tend to be simulations of real world objects: e.g. buildings, cars, and the landscape. In an e-commerce context, consumers may expect interactions with virtual retail environments to be similar to real world retail environments. These expectations relate to the retail environment (e.g. the layout of the aisles and placement of products) as well as the in-store services (e.g. personal sales support).

A design consideration should be on how the environment is deliberately or inadvertently creating expectations for the consumer. The use of metaphors to create expectations is common in design (Ferreira, 2006). When designing ecommerce websites, metaphors are more easily recognised and therefore easier for designers to evaluate. The metaphors on e-commerce websites tend to be confined to icons and clearly defined processes, such as 'the shopping basket' metaphor and 'the checkout' process. However, in virtual worlds, the metaphors are more pervasive. For example, the design of the store itself is a metaphor that creates expectations for consumers.

A large virtual department store will create different expectations for consumers compared to small stores. Consumers may expect to find a wider selection of products in large stores, whereas consumers may expect niche products from smaller stores. Matching or failing to match expectations will influence the consumer's overall evaluation of the consumption experience (Oliver, 1980). Thus, designers should consider how every aspect of store design is setting consumer's expectations. In particular, they should consider how realism is influencing the expectations of consumers. See Reeves and Minocha (2010) for further discussion on elements of realism and fantasy in the design of virtual spaces.

\subsection{Implications of demand for specialised skills and knowledge}

Specialised skills and knowledge is required because of the complexity of the virtual world interface. Novice consumers in virtual worlds may never realise the advantages of virtual worlds for ecommerce if they are not able to learn how to use the interface effectively (Wetsch, 2008). Furthermore, the skills and knowledge required to effectively use virtual worlds for e-commerce go beyond the interface. Virtual worlds are social spaces and therefore require social skills. Consumers need to learn the particular social norms of the virtual world to be able to deal with the social situations that they will inevitably encounter.

A design consideration should be on how to train novice consumers on how to interact with the virtual world interface and how to engage with the virtual world community. Traditional approaches to helping novice users have been to apply usability principles and guidelines related to learnability, documentation and ease-of-use (Nielsen, 2005; Sutcliffe and Gault, 2004; Shneiderman, 2003). These principles and guidelines should still be applied to increase usability of the interface. In particular, improvement is needed for the usability of navigation and avatar control.

Beyond usability, designers should consider how to leverage the skills and knowledge of existing consumers to make it easier for new consumers to learn about virtual worlds. The presence of other, more experienced, consumers should be seen as a valuable resource for enhancing learnability. One way would be to create formal communication 
channels specifically for helping new consumers. This is a strategy used by many online multi-player games, such as World of Warcraft (www.worldofwarcraft.com) and Eve Online (www.eveonline.com). There may be other ways to facilitate and encourage learning between consumers. Insights can be gained from research in persuasive design and social marketing where theories can be applied to facilitate social interaction between consumers (e.g. Chan and Li, 2010).

\section{CONCLUSION AND FUTURE WORK}

The contribution of this study has been to identify affordances of virtual worlds that are relevant for B2C e-commerce. We will continue to examine affordances of virtual worlds to understand which other design implications can be derived. Furthermore, we will produce an empiricallygrounded list of design guidelines targeted for designers and usability practitioners to guide the process of design and evaluation of $\mathrm{B} 2 \mathrm{C}$ ecommerce environments in virtual worlds.

\section{REFERENCES}

Adrian, A. (2008). No One Knows You Are a Dog: Identity and Reputation in Virtual Worlds. Computer Law \& Security Report, 24(4), 366-374.

Anders, P. (1998). Envisioning Cyberspace: Designing 3D Electronic Spaces. London, UK: McGraw-Hill.

Bourlakis, M., Papagiannidis, S., \& Li, F. (2009). Retail Spatial Evolution: Paving the Way From Traditional to Metaverse Retailing. Electronic Commerce Research, 9(1), 135-148.

Braun, V., \& Clarke, V. (2006). Using Thematic Analysis in Psychology. Qualitative Research in Psychology, 3(2), 77-101.

Buetow, S. (2010). Thematic Analysis and Its Reconceptualization as "Saliency Analysis". Journal of Health Services Research \& Policy, 15(2), 123-5.

Chan, K. W., \& Li, S. Y. (2010). Understanding Consumer-to-Consumer Interactions in Virtual Communities: The Salience of Reciprocity. Journal of Business Research, 63(9-10), 1033-1040.

Ganis, M., Hall, G., \& McNeill, D. (2008). Virtual Worlds as Real-World Sales Tools. Cutter IT Journal, 21(9), 19-25.
Goel, L., \& Prokopec, S. (2009). If You Build it Will They Come? An Empirical Investigation of Consumer Perceptions and Strategy in Virtual Worlds. Electronic Commerce Research, 9, 115134.

Ferreira, J., Noble, J., \& Biddle, R. (2006). A Case for Iconic Icons. Proceedings of the 7th Australasian User Interface Conference, 97-100.

Hansen, L. (2009). What Happened to Second Life? BBC News Magazine Nov 20, 2009. Retrieved from http://news.bbc.co.uk/1/hi/magazine/8367957.stm.

Hemp, P. (2006). Are You Ready for E-tailing 2.0? Harvard Business Review October 2006, 28.

Kozinets, R. V. (1999). E-Tribalized Marketing?: The Strategic Implications of Virtual Communities of Consumption. European Management Journal, 17(3), 252-264.

Nielsen, J. (2005). Ten Usability Heuristics. Retrieved May 2, 2011 from http://www.useit.com/papers/heuristic/heuristic_list. html.

O'Keefe, R. M., \& McEachern, T. (1998). Webbased Customer Decision Support Systems. Communications of the ACM, 41(3), 71-78.

Oliver, R. (1980). A Cognitive Model of the Antecedents and Consequences of Satisfaction Decisions. Journal of Marketing Research, 17(4), 460-469.

Park, S. R., Nah, F. F., Dewester, D., \& Eschenbrenner, B. (2008). Virtual World Affordances: Enhancing Brand Value. Journal of Virtual Worlds Research, 1(2), 1-18.

Reeves, A. and Minocha, S (2010). Relating Pedagogical and Learning Space Designs in Second Life. In: Cheney, Amelia and Sanders, Robert eds. Teaching and Learning in 3D Immersive Worlds: Pedagogical Models and Constructivist Approaches. USA: IGI Global.

Shneiderman, B. (2003). Why Not Make Interfaces Better than 3D Reality? IEEE Computer Graphics and Applications, 23(6), 12-15.

Sutcliffe, A., \& Gault, B. (2004). Heuristic Evaluation of Virtual Reality Applications. Interacting with Computers, 16, 831-849.

Wetsch, L. R. (2008). The "New" Virtual Consumer: Exploring the Experiences of New Users. Journal of Virtual Worlds Research, 1(2), 1-12. 